OPEN ACCESS

Edited by:

Adel M. Talaat

University of Wisconsin-Madison, USA

Reviewed by:

Stacey Gilk,

Indiana University School of Medicine,

USA

Torsten Eckstein

Colorado State University, USA

${ }^{*}$ Correspondence:

Marta Alonso-Hearn

malonso@neiker.eus

Received: 12 July 2016 Accepted: 06 March 2017 Published: 21 March 2017

Citation:

Alonso-Hearn M, Abendaño N Ruvira MA, Aznar R, Landin M and

Juste RA (2017) Mycobacterium avium subsp. paratuberculosis (Map)

Fatty Acids Profile Is

Strain-Dependent and Changes Upon Host Macrophages Infection.

Front. Cell. Infect. Microbiol. 7:89.

doi: 10.3389/fcimb.2017.00089

\section{Mycobacterium avium subsp. paratuberculosis (Map) Fatty Acids Profile Is Strain-Dependent and Changes Upon Host Macrophages Infection}

\author{
Marta Alonso-Hearn ${ }^{1 *}$, Naiara Abendaño ${ }^{1}$, Maria A. Ruvira ${ }^{2}$, Rosa Aznar ${ }^{2}$, \\ Mariana Landin ${ }^{3}$ and Ramon A. Juste ${ }^{1,4}$ \\ ${ }^{1}$ Department of Animal Health, NEIKER-Basque Institute for Agricultural Research and Development, Technological Park of \\ Bizkaia, Derio, Spain, ${ }^{2}$ Spanish Type Culture Collection (CECT), University of Valencia, Parc Cientific Universitat de València, \\ Paterna, Spain, ${ }^{3}$ Department of Pharmacology, Pharmacy and Pharmaceutical Technology, University of Santiago, Santiago \\ de Compostela, Spain, ${ }^{4}$ Servicio Regional de Investigación y Desarrollo Agroalimentario, Agri-Food Research and \\ Development Regional Service, Villaviciosa, Spain
}

Johne's disease is a chronic granulomatous enteritis of ruminants caused by the intracellular bacterium Mycobacterium avium subsp. paratuberculosis (Map). We previously demonstrated that Map isolates from sheep persisted within host macrophages in lower CFUs than cattle isolates after 7 days of infection. In the current study, we hypothesize that these phenotypic differences between Map isolates may be driven be the fatty acids (FAs) present on the phosphadidyl-1-myo-inositol mannosides of the Map cell wall that mediate recognition by the mannose receptors of host macrophages. FAs modifications may influence Map's envelope fluidity ultimately affecting pathogenicity. To test this hypothesis, we investigated the responses of two Map isolates from cattle (K10 isolate) and sheep (2349/06-1) to the bovine and ovine macrophage environment by measuring the FAs content of extracellular and intracellular bacteria. For this purpose, macrophages cell lines of bovine (BOMAC) and ovine (MOCL-4) origin were infected with the two isolates of Map for 4 days at $37^{\circ} \mathrm{C}$. The relative FAs composition of the two isolates recovered from infected BOMAC and MOCL-4 cells was determined by gas chromatography and compared with that of extracellular bacteria and that of bacteria grown in Middlebrook $7 \mathrm{H} 9$ medium. Using this approach, we demonstrated that the FAs composition of extracellular and 7H9-grown bacteria was highly conserved within each Map isolate, and statistically different from that of intracellular bacteria. Analysis of FAs composition from extracellular bacteria enabled the distinction of the two Map strains based on the presence of the tuberculostearic acid (18:0 10Me) exclusively in the K10 strain of Map. In addition, significant differences in the content of Palmitic acid and cis-7 Palmitoleic acid between both isolates harvested 
from the extracellular environment were observed. Once the infection established itself in BOMAC and MOCL-4 cells, the FAs profiles of both Map isolates appeared conserved. Our results suggest that the FAs composition of Map might influence its recognition by macrophages and influence the survival of the bacillus within host macrophages.

Keywords: Mycobacterium avium subp. paratuberculosis, Map-host interaction, fatty acids, lipid metabolism, macrophages

\section{INTRODUCTION}

Mycobacterium avium subsp. paratuberculosis (Map) is the etiological agent of Johne's disease (JD) or paratuberculosis, a chronic granulomatous enteritis of ruminants. Map isolates can be classified in two genotypes based on culture characteristics and genome analysis: sheep isolates (also called "type S" or "type I") and cattle isolates (also called "type C" or "type II) (Collins et al., 1990; Bryant et al., 2016). JD causes considerable economic losses to the livestock and associated industries, due to decreased milk production, premature culling, and reduced carcass value (Ott et al., 1999). This, coupled with an association of Map with Crohn's disease and diabetes type I has resulted in an increasing interest in studying JD pathogenesis (Feller et al., 2007; Scanu et al., 2007; Abubakar et al., 2008; Juste et al., 2008, 2009; Naser et al., 2014). Macrophages primarily use the mannose receptor (MR, CD207) as well as the complement 3 receptor for the phagocytosis of Map (Souza et al., 2007). These receptors are distinguished by the fact that they mediate the engulfment of microbes without necessarily inciting a proinflammatory immune response and thereby have long been postulated to enhance early intracellular survival of some microbes. Continued efforts to define the factors affecting the early interaction between Map and host macrophages are necessary to further our understanding of the pathogenesis of paratuberculosis and final disease outcome. This ongoing research might help in the development of better control strategies and diagnostic techniques.

Not only susceptibility of the host but also virulence properties of Mycobacteria contribute to their pathogenicity. Mycobacteria are characterized by a complex cell wall structure rich in lipids that constitute up to $60 \%$ of the dry weight of the organism and that is responsible for many of its unique properties (acid fast staining and resistance to many antibiotics). Among the cell-envelope components, phophatidyl1-myo-inositol mannosides (PIMs) are found in abundant quantities in the cell envelope of all Mycobacterium species (Kolattukudy et al., 1997). PIMs are considered not only essential structural components of the cell envelope but also the precursors of the two major mycobacterial lipoglycans, lipomannan (LM)

Abbreviations: Map, Mycobacterium avium subsp. paratuberculosis; FAs, fatty acids; MR, mannose receptor; PIMs, phosphadidyl-1-myo-inositol mannosides; LM, lipomannan; Man-LAM, lipoarabinomannan; PI, phosphadidyl-myoinositol; TBSA, tuberculostearic acid; Mtb, Mycobacterium tuberculosis; GC, gas chromatography; HBSS, Hank's balanced salt solution; FAMEs, Fatty Acid Methyl Esters; ECL, Equivalent Chain Length; GLM, General Lineal Model; NFL, Neurofuzzy logic. and lipoarabinomannan (Man-LAM). PIMs are based on a phosphadidyl-myo-inositol (PI) lipid carrying one to six $\alpha$-DMan $p$ residues $\left(\mathrm{PIM}_{1}\right.$ to $\left.\mathrm{PIM}_{6}\right)$ and up to four acyl chains, with tri- and tetra-acylated PIM dimannoside $\left(\mathrm{Ac}_{1} \mathrm{PIM}_{2}, \mathrm{Ac}_{2} \mathrm{PIM}_{2}\right)$ and PIM hexamannoside $\left(\mathrm{Ac}_{1} \mathrm{PIM}_{6}, \mathrm{Ac}_{2} \mathrm{PIM}_{6}\right)$ as the most predominant classes of PIMs found in Mycobacterium species (Guerin et al., 2010; Albesa-Jové et al., 2016). In Mycobacterium tuberculosis $(M t b)$, the FAs composition of the tri-acylated forms of the PIMS includes two Palmitic acids and one Tuberculostearic acid (TBSA) (Gilleron et al., 2003). The tetra-acylated forms of the PIMs are present predominantly as two populations bearing either three Palmitic acids/one TBSA or two Palmitic acids/two TBSAs. The Man-LAM Mtb is a bacterial ligand for the entry of $M t b$ into macrophages via the MR, and both the mannose caps and the fatty acids are required for efficient binding (Gilleron et al., 2001; Torrelles et al., 2008). Other major effects attributed to the Man-LAM of $M t b$ in phagocytic cells include induction of a rapid IL-10 expression, suppression of TNF$\alpha$ and IL12 production, inhibition of apoptosis, inhibition of phagosome-lysosome fusion, suppression of oxygen radicals and nitric oxygen generation (Fratti et al., 2003; Majumder et al., 2008). All of these biological activities are abolished with the loss of the fatty acyl appendages, and acylation of a specific site might be important in the context of PIM presentation (Gilleron et al., 2006). The FAs induce a supramolecular organization of Man-LAM in aqueous solution, resulting in the formation of a $30 \mathrm{~nm}$ spherical structure, composed of approximately 450 molecules with the mannose caps exposed at the surface (Rivière et al., 2004). This supramolecular structure allows multipoint attachment of Man-LAM, via mannose caps, to the MR pointing toward the importance of the FAs in the conformation and accessibility of the terminal mannosyl structures (Torrelles et al., 2006; Guerin et al., 2010). Using three dimensional models, Torrelles et al. evaluated how the nature of the FAs in the tetraacylated PIMs affects its spatial conformation (Torrelles et al., 2008). They found that there was a slight effect on the axis when the fourth fatty acid was substituted with Palmitic acid or Oleic acid relative to TBSA. Altogether, these findings reinforce the idea that changes in the FAs composition of Mycobacteria might impact the spatial conformation of the mannose caps for PIMs recognition by the $\mathrm{MR}$.

We previously tested the ability of 10 isolates of Map isolated from domestic (cattle, sheep, and goat) and wildlife animal species (fallow deer, deer, and wild boar) to enter, grow and persist in bovine and ovine macrophages (Abendaño et al., 2013, 2014). Our results demonstrated that the 2349/06-1 isolate of Map (type S) from sheep persisted within bovine macrophages in 
lower CFUs and displayed significantly less growth than the two tested bovine isolates (K10 and 6, type C) after 7 days of infection. Although the variations in the estimated log CFUs at day 7 within ovine macrophages between all the tested isolates were not significant, the bovine isolates proliferated more rapidly than the 2349/06-1 isolate which was observed to minimally decrease in $\log$ CFUs over 7 days from baseline. Analysis of the mechanisms through which Map interferes with macrophage activation and phagosome maturation has shown that engagement of specific membrane receptors with bacterial ligands is the initiating event. Among the cell envelope components of Map, the Man-LAM has been identified as one of the main bacterial ligands involved in phagosome-lysosome inhibition, and as a major virulence factor in determining the capacity of Map to persist within bovine macrophages (Souza et al., 2013). Since data from studies with $M t b$ suggested that the type of the fatty acyl groups present in the PIMs affect their conformation and the subsequent interaction of the mannose caps with the MR, in the current study FAs profiling of Map isolates was performed.

\section{MATERIALS AND METHODS}

\section{Cell Lines}

A SV-40 transformed bovine peritoneal macrophage cell line (BOMAC), was obtained from Judith Stabel (USDA, Ames, IA, US) and maintained as previously described (Stabel and Stabel, 1995). An ovine blood macrophage-like cell line (MOCL-4) was obtained from Michel Olivier (INRA, Nouzilly, France) and cultured as previously described (Olivier et al., 2001).

\section{Map Isolates, Bacterial Culture and Preparation of Bacterial Suspensions}

Two Map isolates from cattle (Bos taurus) and sheep (Ovis aries) were selected from the collection of isolates of the Mycobacteria laboratory, NEIKER-Tecnalia. The bovine K10 isolate of Map, a sequenced strain recovered from a clinical case of paratuberculosis, was obtained from the American Type Culture Collection. The Map 2349/06-1 isolate from sheep was kindly provided by A. C. Coelho. Isolate code, country of isolation, and genotype for each Map isolate are summarized in Table 1. Entry and intracellular growth of the K10 and 2349/06-1 isolates of Map in bovine and ovine macrophages was previously estimated (Abendaño et al., 2013, 2014) and is presented in Table 1. Both Map isolates were maintained as glycerol stock at $-80^{\circ} \mathrm{C}$ (Adúriz et al., 1995; Sevilla et al., 2005, 2007). Aliquots of these glycerol stocks were utilized to directly inoculate all subsequent cultures for use in macrophages infections. The isolates of Map selected for our study were grown in T25 tissue culture flasks at $37 \pm 1^{\circ} \mathrm{C}$ in $10 \mathrm{ml}$ of Middlebrook $7 \mathrm{H} 9$ broth (Difco Laboratories, Detroit, MI) supplemented with $10 \%$ (v/v) oleic acid-albumin-dextrose-catalase (Becton, Dickinson and Company, Franklin Lakes, NJ), 0.05\% (v/v) Tween-80 (Sigma-Aldrch, St Louis, MO) and $2 \mathrm{mg} \mathrm{l}^{-1}$ of Mycobactin J (Allied Monitor Inc., Fayette, MO) for 20 days at $37^{\circ} \mathrm{C}$. Bacterial cells were harvested by centrifugation at $2000 \times \mathrm{g}$ for 20 min in a Beckman Coulter Allegra X-12 centrifuge. Bacterial pellets were washed three times with sterile Hank's balanced salt solution (HBSS), resuspended in $2 \mathrm{ml}$ of HBSS, and the resultant suspension was passed 20 times through a 27 -gauge needle, and large aggregates were allowed to settle. After $5 \mathrm{~min}$, an aliquot was taken from the top half of the bacterial suspension and diluted in HBSS to a McFarland standard of $1\left(310^{8} \mathrm{CFUs} / \mathrm{ml}\right)$ with a Densimat (bioMerieux, Marcy l'Étoile, France). Only the top fraction of the suspension containing dispersed bacteria was used for the infection assays.

\section{Infection of BOMAC and MOCL-4 Cell Lines with Map}

Confluent monolayers of BOMAC and MOCL-4 cell lines grown in a $125-\mathrm{cm}^{2}$ cell culture flask (Corning Costar, New York, US) at $37^{\circ} \mathrm{C}$ in a $5 \% \mathrm{CO}_{2}$ were infected with each of the two Map isolates at MOI of 1:10 (cell:bacteria). At $4 \mathrm{~h}$ postinfection, the medium was collected, centrifuged at $2000 \mathrm{~g}$ for 15 min in a Beckman Coulter Allegra X-12 centrifuge and the resultant pellet containing extracellular bacteria was frozen at $-80^{\circ} \mathrm{C}$. Cell monolayers were washed twice with $20 \mathrm{ml}$ of HBSB and then treated with $200 \mu \mathrm{g} / \mathrm{ml}$ amikacin (Sigma) in HBSB to kill extracellular bacteria. After $2 \mathrm{~h}$ at $37^{\circ} \mathrm{C}$, the amikacin was removed, the monolayers were washed twice with HBSS and fresh culture medium was added to the monolayers. After 4 days at $37^{\circ} \mathrm{C}$, intracellular bacteria were released by lysing the monolayers with sterile water. Cell debris and nuclear fractions were removed by low-speed centrifugation at $400 \mathrm{~g}$ for $5 \mathrm{~min}$ at $4^{\circ} \mathrm{C}$. The bacterial fraction was recovered from the supernatant after additional centrifugation at $2000 \mathrm{~g}$ for $15 \mathrm{~min}$.

\section{Fatty Acid Methyl Esters (FAMEs) Extraction}

FAMEs were extracted from bacterial pellets by saponification with sodium hydroxide in methanol, methylated with hydrochloric acid in methanol and then extracted with hexane in methyl-tert-butyl-ether (Sasser, 1990). Briefly, $1 \mathrm{ml}$ of $15 \%(\mathrm{w} / \mathrm{v}) \mathrm{NaOH}$ in $50 \%$ aqueous methanol was added to each bacterial pellet and incubated at $100^{\circ} \mathrm{C}$ for $30 \mathrm{~min}$ in a water bath. The saponified samples were then cooled in a pan of cold tap water for $2 \mathrm{~min}$, acidified and methylated by the addition of $2 \mathrm{ml}$ of $54 \% 6 \mathrm{~N} \mathrm{HCl}$ in $46 \%$ methanol, and incubated at $80^{\circ} \mathrm{C}$ for $10 \mathrm{~min}$ in a water bath. This step drops the $\mathrm{pH}$ of the solution below 1.5 and cause methylation for the increased volatility in a partially polar column of the FAMEs. The methylated FAMEs were then incubated with $1.25 \mathrm{ml}$ of an organic solvent [hexane:methyl-tert-butyl ether (1:1)]. Each sample was mixed for $10 \mathrm{~min}$ and the lower phase was removed with a Pasteur pipette. The upper phase was washed with $3 \mathrm{ml}$ of $0.3 \mathrm{M} \mathrm{NaOH}$ to remove both free FAMEs and residual reagents. Following the wash step, the organic phase containing the FAMEs was transferred into a GC vial. FAMEs are more volatile than their respective FAs and therefore more suitable for GC analysis.

\section{GC Analysis}

The FAMEs were analyzed by GC using the Agilent 6850 gas chromatographic unit equipped with a crossslinked 5\% phenylmethyl silicone-fused silica capillary column $(25 \mathrm{~m} \times 0.2$ 


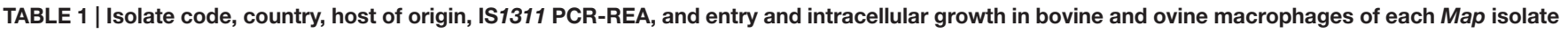
used in the current study.

\begin{tabular}{|c|c|c|c|c|c|c|c|}
\hline \multirow[t]{2}{*}{ Isolate } & \multirow[t]{2}{*}{ Country } & \multirow[t]{2}{*}{ Host } & \multirow[t]{2}{*}{ PCR-REA type } & \multicolumn{2}{|c|}{ Bovine macrophages ${ }^{a}$} & \multicolumn{2}{|c|}{ Ovine macrophages ${ }^{b}$} \\
\hline & & & & Entry (\%) & Growth changes ${ }^{c}$ ( $n$-fold) & Entry (\%) & Growth changes $^{c}$ (n-fold) \\
\hline K10 & US & Cattle & $\mathrm{C}$ & 70.91 & 1.84 & 65.32 & 1.63 \\
\hline 2349/06-1 & Portugal & Sheep & $S$ & 61.69 & 1.31 & 51.93 & 0.99 \\
\hline
\end{tabular}

${ }^{a}$ According to Abendaño et al. (2013).

${ }^{b}$ According to Abendaño et al. (2014).

${ }^{c}$ Growth changes ( $n$-fold) were calculated by dividing the number of $\log { }_{10}$ CFU at day 7 by that at day 0 .

mm, Agilent 19091B-102E), a flame ionization detector and an Agilent 6850 automatic liquid sampler. The column temperature ramped from 170 to $270^{\circ} \mathrm{C}$ at $5^{\circ} \mathrm{C} \mathrm{min}^{-1}$, then increased to $310^{\circ} \mathrm{C}$ at $40^{\circ} \mathrm{C} \mathrm{min}^{-1}$ and held for $1.5 \mathrm{~min}$. Hydrogen served

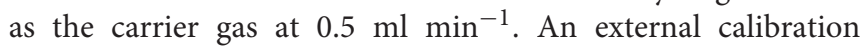
standard, a mixture of straight chain saturated FAs from 9 to 20 carbons in length (9:0 to 20:0) and five hydroxyl acids (Sherlock MIS Calibration Standard, Part\#1200-A, MIDI Inc., Newark, DE, US), was used. The hydroxyl compounds are especially sensitive to changes in pressure/temperature relationships and to contamination of the injection port lines. As a result, these compounds function as real-time quality control checks for the system. Retention time data obtained by injecting the calibration standard is converted to Equivalent Chain Length (ECL) data for bacterial FAs naming. The Retention factor (RFact) for each FA can be derived as a function of its elution time in relation to the elution time of the known series of straight chain FAs. GC allows windows to be set at 0.010 ECL units, giving great resolution of FAs isomers.

FAs analysis using the Sherlock ${ }^{\circledR}$ Microbial Identification software was used to automatically name and quantitate the peaks in an unknown sample (MIDI Inc, Newark, DE, US). The FAMEs extraction procedure may carry over sterols and other nonfatty acid material. Additionally, electronic noise may result in transient spikes, which might interfere with the chromatography. However, FAs peaks always have area/height ratios greater than 0.017 and less than 0.070 , making it possible to set exclusionary parameters at these levels. Electronic noise spikes are typically $<0.017$ and non-fatty acid peaks are usually $>0.070$, allowing rejection of these artifacts. The Sherlock approach is set to use a "Summed in Feature" wherever imperfect peak separation occurs. Reproducibility of the profiles was calculated by comparing two different FAMEs extracts.

\section{FAs Profile Pattern Recognition and Cluster Analysis}

The Sherlock ${ }^{\circledR}$ Microbial Identification System with covariance matrix, principal component analysis and pattern recognition software was used to generate FAs profiles for our samples. The covariance matrix takes into account the mole-for-mole relationship of the conversion of one FA to another which might occur in relation to a temperature shift. The pattern recognition uses ratios between FAs amounts in addition to the principal component base. The dendrogram and principal component analysis (2-D plots) programs of the Sherlock ${ }^{\circledR}$ Microbial Identification System use data from FAs analyses to graphically illustrate relationships between the samples. The dendrogram analysis produces unweight pair matching based on FAs composition. In a dendrogram, the Euclidean distance is the distance in $\mathrm{n}$-dimensional space between two bacterial samples when their FAs composition is compared. Lower linkages indicate greater similarity. In addition to dendrogram, the 2-D Plot is another cluster analysis tool which uses a principal components analysis of FAs profiles to group entries in a two dimensional space. The $\mathrm{x}$-axis represents principal component 1 , and the $\mathrm{y}$-axis represents principal component 2.

\section{Statistical Analysis}

The percentage of 21 FAs in the K10 (type-C) and 2349/06-1 (type-S) isolates of Map under different environmental conditions (extracellular, intracellular, or 7H9 medium) were compared with the General Lineal Model (GLM) procedure of the SAS statistical package version 9.3 (SAS Institute Inc., Cary, NC). Differences were considered significant when $P$-values were $<0.05$. Correlations between FAMEs profiles were examined with the principal components procedure of the SAS software.

\section{Neurofuzzy Logic (NFL) Analysis}

The percentages of each of the 21 FAs in the K10 (type-C) and 2349/06-1 (type-S) isolates of Map under different environmental conditions (BOMAC, MOCL-4), and localizations within the host cell (extracellular and intracellular) were modeled using the NFL FormRules ${ }^{\circledR}$ software v4.03 (Intelligensys Ltd., 2013, Stokesley, UK). The FormRules software contains various statistical fitness criteria including Cross Validation, Minimum Description Length, Structural Risk Minimization, Leave One Out Cross Validation and Bayesian Information Criterion. All were analyzed in order to generate the model with the best predictability together with the simplest and more intelligible rules. The predictability of the model was assessed using correlation coefficient $\left(\mathrm{R}^{2}\right)$ and ANOVA F-values for the percentage of each fatty acid.

$$
R^{2}=\left(\frac{1-\sum_{i=1}^{n}\left(y_{i}-y_{i}^{\prime}\right)^{2}}{\sum_{i=1}^{n}\left(y_{i}-y^{\prime \prime}{ }_{i}\right)^{2}}\right) \times 100 \%
$$


Where $y^{\prime \prime}$ is the mean of the dependent variable, and the $y^{\prime}$ is the predicted value calculated by the model. ANOVA $F$-values over its critical values for the corresponding degrees of freedom are an indication of reasonable model predictabilities (Colbourn and Rowe, 2009). For each of the generated rule a "membership degree" or confidence level is defined which specifies how a "value" belongs to that fuzzy subset (from 0 to 1 ).

\section{RESULTS}

\section{FAs Profiles of Map Isolates Grown in Middlebrook 7H9 Broth}

A representative chromatogram for each Map isolate (K10 and 2349/06-1) grown in Middlebrook 7H9 medium is presented in Figure 1S. The identities of 97.51 and $87.87 \%$ FAs of the K10 and 2349/06-1 isolates were confirmed respectively by demonstrating retention times similar to those of known standards. The peak, $\mathrm{R}$ Factor, systematic name, usual name and relative frequency of each identified FA are summarized in Table 2. FAs found ranged from 9 to 20 carbon atoms. They consisted of nine saturated FAs (9:0, 10:0, 12.0, 14:0, 15:0, 16:0, 17.0, 18:0, 20:0), six monounsaturated FAs (16:1 w9c, 16:1 w7c, 16:1 w6c, 17:1 w8c, 18:1 w9c, 18:1 w7c), one double-unsaturated FA (18:2 w6,9c), one 10-methyl branched of 18 carbon atoms (18:0 10Me) and three Sum in Feature FAs. The Palmitic acid (16:0) and Oleic acid (18:1 w9c) were the most abundant FAs and together represented more than $50 \%$ of the total cellular FA content of both Map isolates. From the 21 identified FAs, 14 were present in the profiles of both
Map strains. The K10 isolate was characterized by the presence of four FAs (9:0, cis-10-Palmitoleic acid, Summed in Feature 1, and TBSA) which were absent in the 2349/06-1 isolate. The 16:0 2,4 DiMe was detected in very small amount only in the S-type isolate of Map. Statistical analysis of the FAs composition of both Map isolates grown in Middlebrook 7H9 medium (Figure 1) enabled the distinction between both Map strains based on the presence of the TBSA (18:0 10Me) exclusively in the C-type isolate of Map. Among the 14 FAs present in the profiles of both Map isolates, significant differences were observed in the abundances of Palmitic acid and TBSA between both Map isolates.

\section{FAs Content of Map Isolates in the Extra- and Intracellular Environment of BOMAC and MOCL-4 Cells}

To evaluate whether the extra- and/or the intracellular environment influences Map FAs composition, BOMAC and MOCL-4 cells were infected with the K10 and the 2349/06-1 isolates of Map. At $4 \mathrm{~h}$ post-infection, the medium was collected, centrifuged at $2000 \mathrm{~g}$ for $15 \mathrm{~min}$ and the FAMEs of the bacterial pellet extracted. After 4 days at $37^{\circ} \mathrm{C}$, intracellular bacteria were recovered by differential centrifugation after lysing the infected monolayers. FAMEs were extracted from extra- and intracellular bacteria and analyzed by GC (Figures $2 \mathrm{~S}, 3 \mathrm{~S}$ ). The percentages of the FAs found in both isolates recovered from the extra- and intracellular environment of BOMAC and MOCL-4 cells are reported in Table 3. The FAs profiles of both Map isolates grown

TABLE 2 | Peak, R Factor, and FAs analysis of the K10 and 2349/06-1 isolates of Map grown in 7H9 medium.

\begin{tabular}{|c|c|c|c|c|c|}
\hline Peak & Systematic name & Usual name & RFactor & K10 & 2349/06-1 \\
\hline 10:0 & Decanoic acid & Capric acid & 1.208 & & \\
\hline 12:0 & Dodecanoic acid & Lauric acid & 1.054 & 0.20 & 0.23 \\
\hline $14: 0$ & Tetradecanoic acid & Myristic acid & 0.973 & 3.26 & 2.75 \\
\hline $16: 1 w 9 c$ & (7Z)-7-Hexadecenoic acid & cis-7-Palmitoleic acid & 0.937 & 8.16 & 2.53 \\
\hline $16: 1$ w7c & (9Z)-9-Hexadecenoic acid & Palmitoleic acid & 0.937 & 1.27 & 3.87 \\
\hline $16: 1 w 6 c$ & (10Z)-10-Hexadecenoic acid & cis-10-Palmitoleic acid & 0.936 & 1.31 & \\
\hline $16: 0$ & Hexadecanoic acid & Palmitic acid & 0.935 & 22.54 & 37.95 \\
\hline $17: 1$ w8c & (9Z)-9-Heptadecenoic acid & cis-Margoreleic acid & 0.933 & & \\
\hline Sum in Feature 1 & 16:0 8ME/16:0 10ME & & 0.930 & 0.35 & \\
\hline $18: 2 w 6,9 c$ & 1,1,-Dimerthoxyoctadecadiene & & 0.921 & 0.68 & 0.63 \\
\hline $18: 1$ w9c & (9Z)-9-Octadecenoic acid & Oleic acid & 0.921 & 28.51 & 34.23 \\
\hline $18: 1 w 7 c$ & (11Z)-11-Octadecenoic acid & cis-Vaccenic acid & 0.920 & 1.36 & 1.81 \\
\hline 18:0 & Octadecanoic acid & Stearic acid & 0.919 & 7.79 & 6.34 \\
\hline 18:0 10Me & 10-Methyloctadecanoic acid & TBSA & 0.918 & 8.97 & \\
\hline Sum in Feature 3 & 20:0 ALC/18.838ECL/19:0 Cycloprop w10c/19:0 Cycloprop w8c & & 0.916 & 9.95 & 4.74 \\
\hline 20:0 & Icosanoic acid & Arachidic acid & 0.909 & 1.81 & 1.46 \\
\hline
\end{tabular}

a Relative amount of each FA is expressed as a percentage of the total FAs content. 


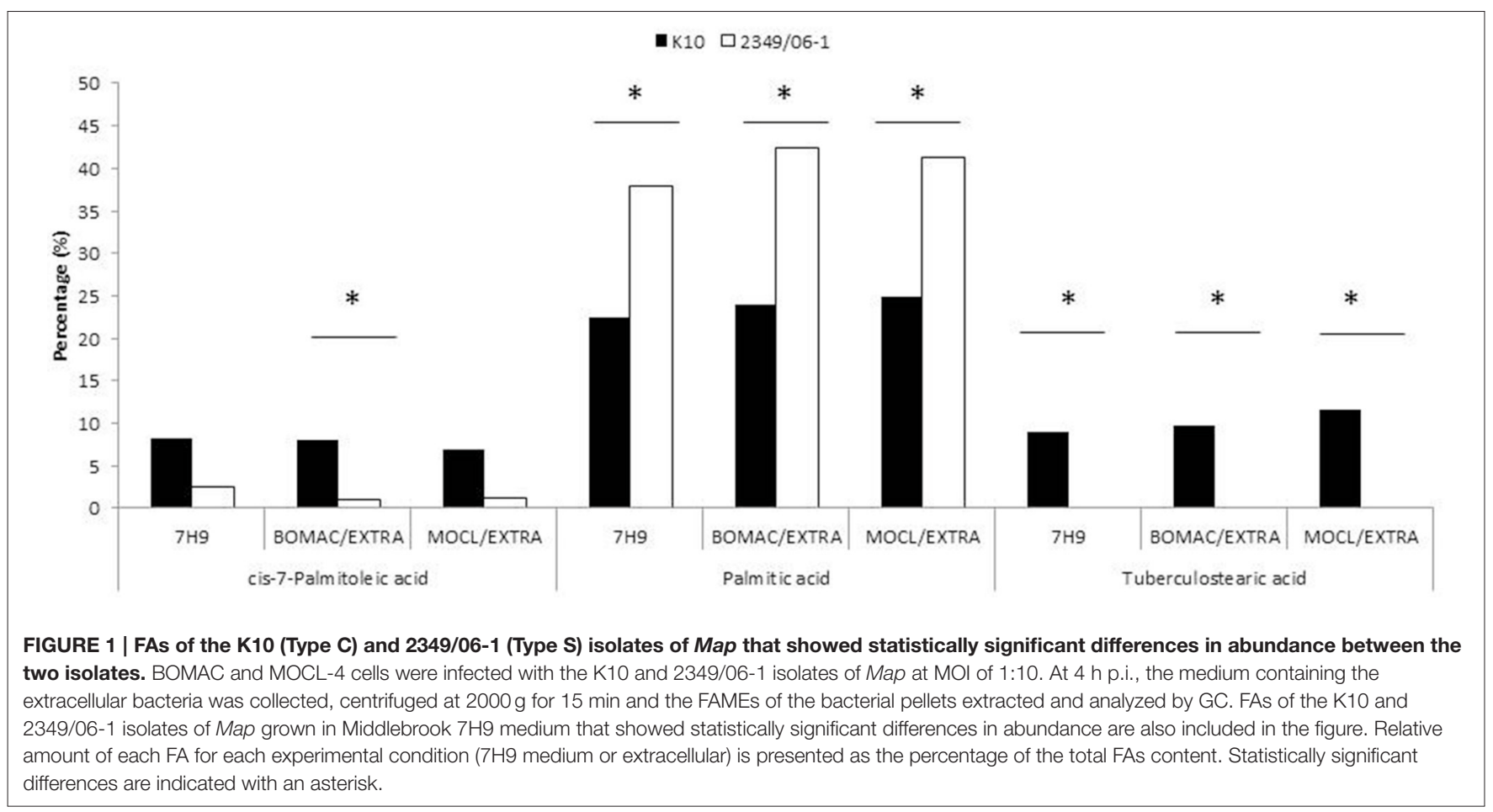

TABLE 3 | Comparative FAs profiles of intracellular K10 and 2349/06-1 isolates of Map recovered from BOMAC and MOCL-4 cells at 4 d p.i. vs. extracellular bacteria.

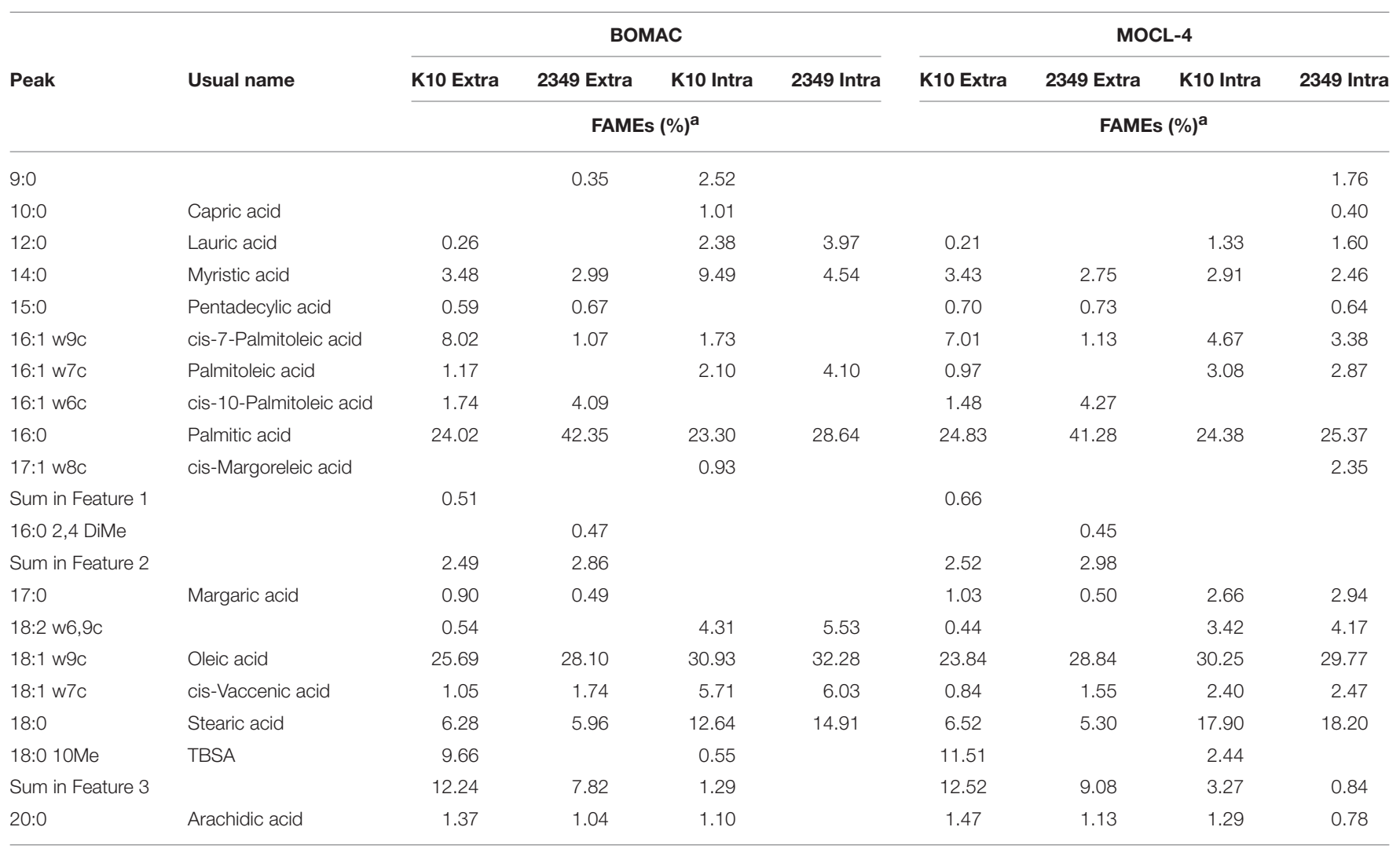

${ }^{a}$ Relative amount of each FA is expressed as a percentage of the total FAs content. 
in 7H9 medium and recovered from the extracellular medium of BOMAC or MOCL-4 cells were found to be highly similar. As shown in Figure 1, the amount of Palmitic acid and TBSA was quite different in both isolates of Map recovered from the extracellular environment regardless of the cell line. Significant differences in the content of cis-7-Palmitoleic acid between both isolates of Map were only observed in the bacteria recovered from the extracellular environment of BOMAC cells. When comparing the FAs profiles of each Map isolate recovered from the extra- or intracellular environment of BOMAC and MOCL- 4 we observed that Map FAs profiles change upon host macrophages infection and that these changes are strain-dependent (Figure 2). Since the K10 and 2349/06-1 isolates recovered from the extracellular environment showed a different FAs profile they had to re-align their FAs metabolism inside host macrophages in a different manner. Once within host macrophages, FAs profiles of both Map isolates were equivalents regardless of the cell line.

\section{Clustering Analysis}

The dendrogram and 2D-plots derived from the FAs profiles of both isolates under the three assessed environmental conditions (extra, intra, and 7H9 grown) are presented in Figures 3A,B, respectively. FAs profiles were clustered into three groups. The first group consisted of the FAs profiles of the K10 and 2341/06-1 isolates recovered from the intracellular environment of BOMAC and MOCL- 4 cells. The FAs profiles in the first group were

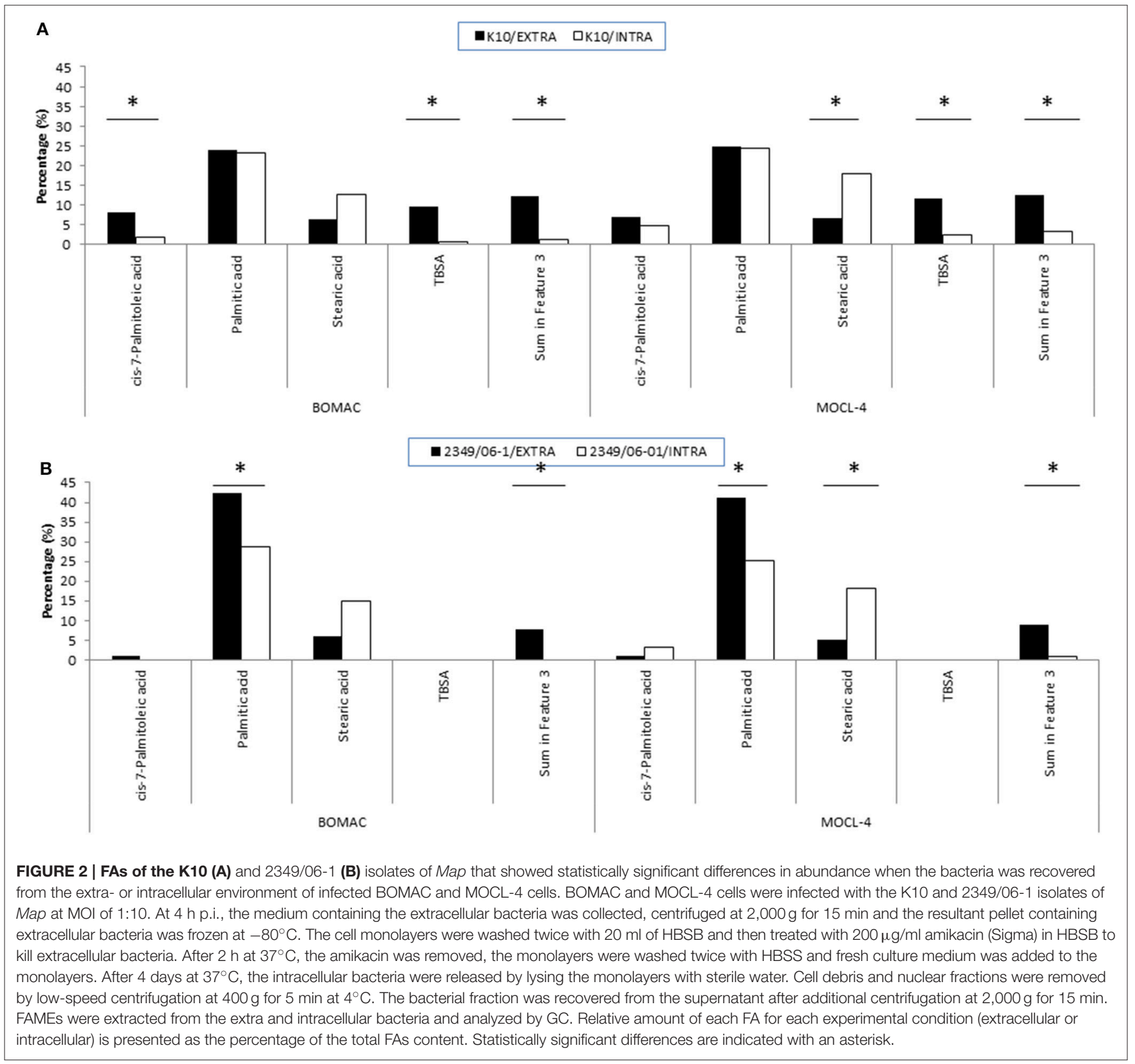




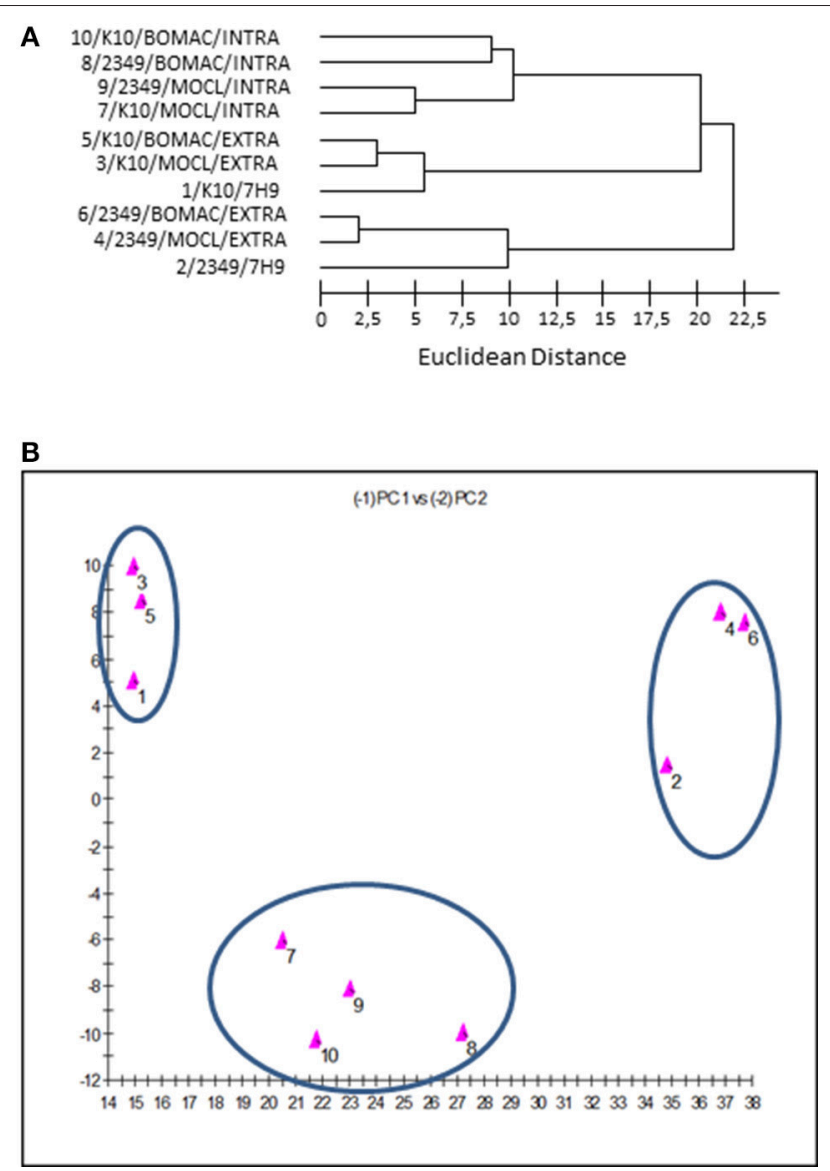

FIGURE 3 | (A) Dendrogram generated using the Sherlock Microbial Identification System with the FAs profiles of the K10 and 2349/06-1 isolates of Map under the three assessed environmental conditions (extracellular, intracellular, and $7 \mathrm{H} 9$ Middlebrook). The Euclidean distance is the distance in $\mathrm{n}$-dimensional space between the bacterial samples when their FAs composition is compared. Lower linkages indicate greater similarity (B). Two dimensional-plot based on principal-component analysis of the FAs profiles of the $\mathrm{K} 10$ and 2349/06-1 isolates of Map under the three assessed environmental conditions (extracellular, intracellular and $7 \mathrm{H} 9$ grown). The $\mathrm{x}$-axis represents principal component 1 (PC1) and the $\mathrm{y}$-axis represents principal component 2 (PC2).

clustered into two subgroups according to subtle differences of FAs depending of the host cell line.

The second group includes the FAs profiles of the K10 strain grown in $7 \mathrm{H} 9$ medium or recovered from the extracellular medium of infected BOMAC or MOCL- 4 cells. The common feature of this group is that the amount of Palmitic acid and TBSA was different than the 2341/06-1 isolate which was clustered in a third group. Although the extracellular and 7H9-grown bacteria belonged to the same cluster, they formed two separate subgroups that reflected environmental divergence. The FAs profiles of each isolate of Map recovered from the extracellular environment of BOMAC and MOCL-4 cells were very similar, and the analysis could not differentiate these two extracellular environments. An excellent correlation between the two-dimensional plots obtained with the principal components procedures of the
Sherlock Microbial Identification System and the SAS software was obtained.

\section{Neurofuzzy Logic (NFL) Analysis}

In order to understand how the different environmental conditions (BOMAC, MOCL-4), and localization within the host cell (extra- and intracellular) contribute alone or in combination to the amount each of the 21 FAs identified in the K10 and 2349/06-1 isolates of Map, our data were modeled using the NFL FormRules ${ }^{\circledR}$ software v4.03 (Intelligensys Ltd., 2013, Stockesley, UK). Within the statistical fitness criteria included in this software, Structural Risk Minimization was selected to give our model with the best predictability and, simultaneously, the simplest and more intelligent rule sets. This approach allowed the discrimination of the inputs (host of origin of each isolate, genotype, cell line, and localization) which more accurately explained the variability of the amount of each identified FA. For instance, the effect of the Map isolate (K10 or 2349/06-1) and its localization within the host cell (extraor intracellular) determined the variability in the amount of cis-7-Palmitoleic acid, Palmitic acid and TBSA (Figure 4). NFL technology generated a set of "IF...THEN" rules per submodel with their corresponding membership degrees (Table 4). These rule sets represent the cause-effect relationships of the different inputs on the percentage of each FA. For example, for Rule 9: "If the isolate is the $\mathrm{K} 10$ and if it is localized in the extracellular environment of the host cell then the amount of TBSA is high with a confidence level of membership of 0.92." In contrast, if the isolate is the 2349/06-1 the amount of TBSA is low with a confidence level of membership of 1.00 (Rule 10). Interestingly, the only factor explaining the variability in the amount of the Stearic acid and Sum in Feature 3 of Map was the bacterial localization, extra- or intracellular.

\section{DISCUSSION}

Much of what is known of the roles of PIMs in Mycobacteriahost interaction is derived from in vitro studies using various cell models and purified PIMs molecules or whole mycobacterial cells (Guerin et al., 2010; Torrelles and Schlesinger, 2010). In $M t b$, the nature of its FAs has been shown to impact the spatial conformation of the PIMs mannose caps for recognition by the $\mathrm{MR}$, the host immune response and the fate of the bacillus within human macrophages (Torrelles et al., 2008). In the current study, comparative FAs profiling was performed to detect differences between a bovine and an ovine isolate of Map before and after entry within macrophages. FAs analysis allows us to consider not only the presence or absence of each FA but also use the data in a quantitative fashion. Previously, a set of 10 FAs (14:0, 16:1w7c, 16:1w6c, 16:0, 18:2w6,9c, 18:1w9c, 18:0, 18:0 10 Me, Summed in Feature 2 and Summed in Feature 3) were found in five Mycobacterium avium complex strains, which were differentiated from $M t b$ and Mycobacterium xenopi strains by the presence of Palmitoleic acid (16:1 w7c), and Summed in Feature 2 and 3 (Ozbek and Aktas, 2003). As a result, it was suggested that these three FAs could be used as markers to identify 
A

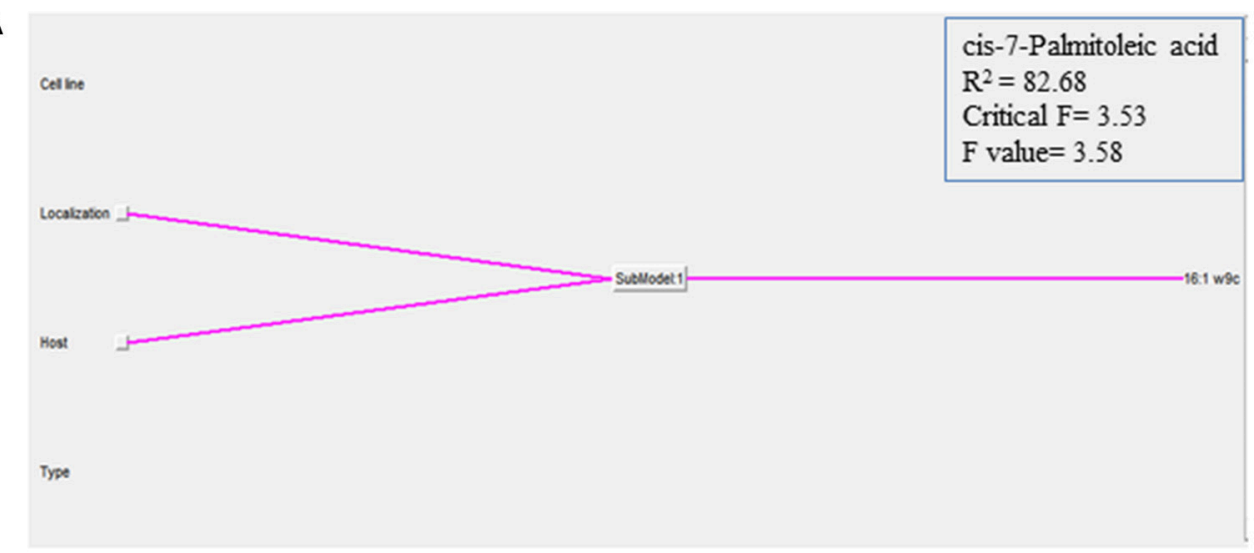

B

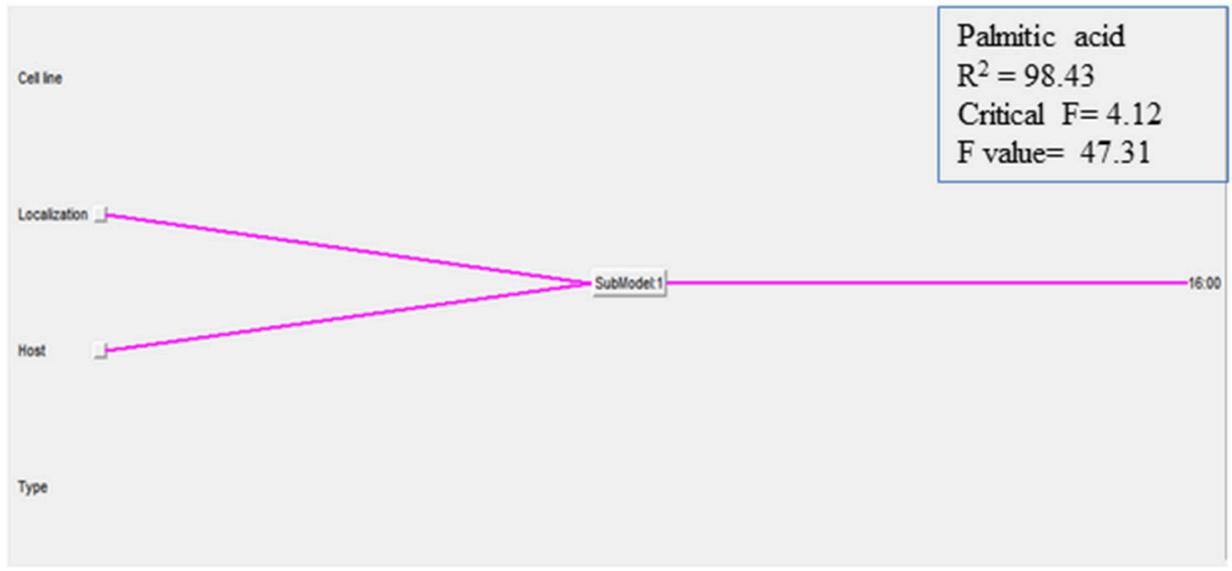

C

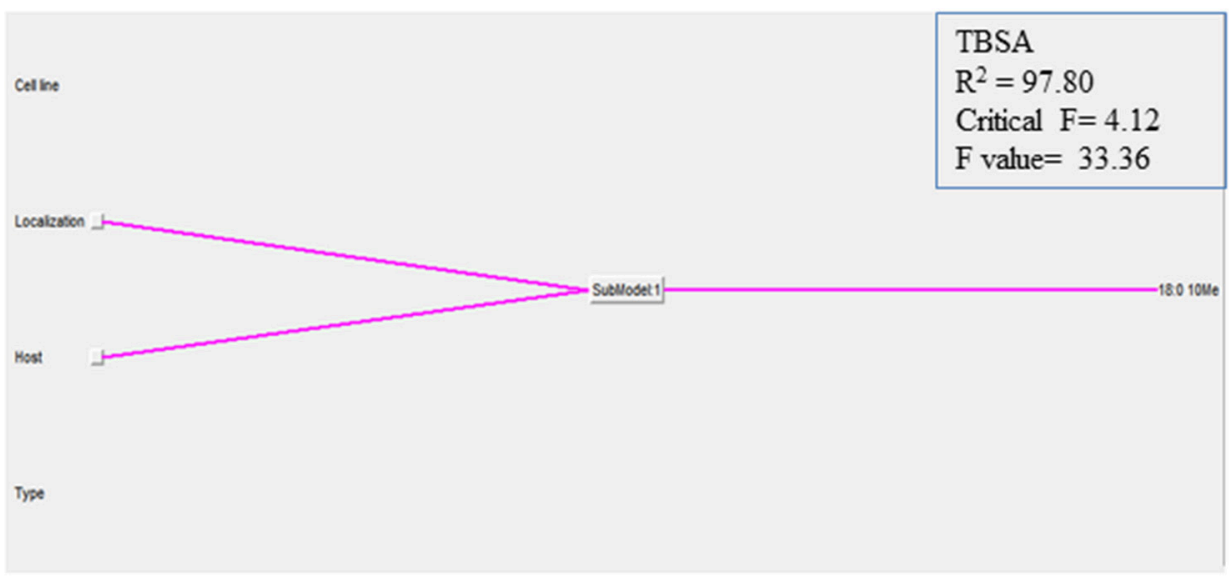

FIGURE 4 | Graphical representation of the NFL models generated for the (A) cis-7-Palmitoleic acid, (B) Palmitic acid, and (C) TBSA; the percentages of each of the 21 identified FAs in the K10 and 2349/06-1 isolates of Map recovered from two localizations (extra- and intracellular) of two host cell lines (BOMAC and MOCL-4) were modeled using the NFL FormRules software v4.03. The effect of the specific Map isolate (bovine or ovine) and its localization within the host cell (extracellular or intracellular) determined the amount of the three presented Map FAs. The predictability of each submodel was assessed using correlation coefficient $\left(\mathrm{R}^{2}\right)$ and ANOVA $F$-values for the percentage of each FA. ANOVA $F$-values over its critical values are an indication of reasonable model predictabilities.

and distinguish Mycobacterium avium complex strains from other Mycobacteria. Our results agreed with these observations because the Palmitoleic acid, Summed in Feature 2 and 3 were consistently identified in the two Map isolates tested in the current study.
The percentage of the 21 identified FAs in the K10 and 2349/06-1 isolates of Map under different environmental conditions (extracellular, intracellular, or 7H9 medium) were used to generate a statistical GLM. The GLM provided evidence that the lack of TBSA and a significant increased Palmitic acid 
TABLE 4 | Rules generated by the neurofuzzy logic model.

\begin{tabular}{|c|c|c|c|c|c|}
\hline Fatty acid & Rule & Map isolate & Localization & $\begin{array}{l}\text { Percentage } \\
\text { (\%) }\end{array}$ & $\begin{array}{c}\text { Confidence } \\
\text { level }\end{array}$ \\
\hline \multicolumn{6}{|l|}{$16: 1$ w9c } \\
\hline \multirow{4}{*}{$\begin{array}{l}\text { cis-7 Palmitoleic } \\
\text { acid }\end{array}$} & 1 & K10 & Extra & $\mathrm{HIGH}$ & 0.94 \\
\hline & 2 & 2349/06-1 & Extra & LOW & 0.86 \\
\hline & 3 & K10 & Intra & LOW & 0.60 \\
\hline & 4 & 2349/06-1 & Intra & LOW & 0.79 \\
\hline \multicolumn{6}{|l|}{$16: 0$} \\
\hline \multirow[t]{4}{*}{ Palmitic acid } & 5 & K10 & Extra & LOW & 0.94 \\
\hline & 6 & 2349/06-1 & Extra & $\mathrm{HIGH}$ & 0.97 \\
\hline & 7 & K10 & Intra & LOW & 0.97 \\
\hline & 8 & 2349/06-1 & Intra & LOW & 0.81 \\
\hline \multicolumn{6}{|l|}{ 18:0 10Me } \\
\hline \multirow{4}{*}{$\begin{array}{l}\text { Tuberculostearic } \\
\text { acid }\end{array}$} & 9 & K10 & Extra & $\mathrm{HIGH}$ & 0.92 \\
\hline & 10 & 2349/06-1 & Extra & LOW & 1.00 \\
\hline & 11 & K10 & Intra & LOW & 0.87 \\
\hline & 12 & 2349/06-1 & Intra & LOW & 1.00 \\
\hline \multicolumn{6}{|l|}{$18: 0$} \\
\hline \multirow[t]{2}{*}{ Stearic acid } & 13 & & Extra & LOW & 0.94 \\
\hline & 14 & & Intra & $\mathrm{HIGH}$ & 0.82 \\
\hline \multicolumn{6}{|c|}{ SUM IN FEATURE 3} \\
\hline & 15 & & Extra & $\mathrm{HIGH}$ & 1.00 \\
\hline & 16 & & Intra & LOW & 1.00 \\
\hline
\end{tabular}

content correlated with the significant decrease of survival of the 2349/06-1 isolate of Map within macrophages when compared with the K10 strain. Our data was also modeled using the NFL technology which is able to model complex non-linear relationships hidden in data, having a higher accuracy in prediction than classical statistics and helping the understanding of the complex relationships between variables (Shao et al., 2006; Landín et al., 2009; Gago et al., 2010). The rule sets generated with the logic model were in agreement with the findings based on statistical analysis confirming differences in the FAs profiles of both isolates of Map in the extracellular environment of the host cell. Previously, a slight effect on the axis of the $\mathrm{Ac}_{2} \mathrm{PIM}_{6}$ of $M t b$ was observed when the fourth FA was substituted with Palmitic acid or Oleic acid relative to TBSA (Torrelles et al., 2008). Accordingly, we suggest that the lack of TBSA or its replacement may affect the ability of Map to infect and to survive within host macrophages. Subtle changes in the FAs composition of Map might alter: (i) the amount of Man on the cell surface, and/or (ii) might cause a different spatial conformation, disposition and/or localization of Man within the cell envelope of Map.

TBSA is a lipid tail of PMIs reported as a constituent of the cell wall of the genus Mycobacterium, including Mtb (Odham et al., 1979; Lambert et al., 1986) and other phylogenetically related organisms within the suborden Corynebacterineae including the genera Nocardia, Corynebacterium, Gordonia, and Turicella but not in mammalian hosts (Luquin et al., 1991). For this reason, the detection of TBSA with GC has been used for rapidly diagnosing pulmonary $M t b$ infection (Cai et al., 2013; Dang et al., 2015). Apart from Mycobacterium gordonae, the other species of low pathogenic Mycobacterium that has been reported to lack TBSA is Mycobacterium leprae (Asselineau et al., 1981; Chiodini and Van Kruiningen, 1985). In our study, we found that the TBSA was present in the K10 strain of Map (type C) but consistently absent in the 2349/06-1 isolate (type S). Therefore, we propose that this FA could be used as a suitable chemical marker for discrimination between the two genotypes of Map. However, we recognize that further studies with multiple isolates of the same host origin and of different genotypes are needed to sustain this assumption.

The ability to remodel the bacterial cell wall in accordance with the changing environmental conditions (i.e., temperature, osmolarity, $\mathrm{pH}$, and concentrations of specific ions) is an essential adaptative strategy for bacterial pathogens. Gramnegative bacteria with both environmental and mammalian reservoirs can synthesize modified forms of lipid A, the biologically active component of the lipopolysaccharide of the outer membrane, in response to environmental stimuli and temperature change (Li et al., 2012). Even small modifications to the outer membrane composition, such as shortening/lengthening acyl chains components of the Lipid A, can alter the bacterium's outer membrane integrity, immune stimulation and pathogenesis. Previous studies highlighted a response of $M t b$ to the intramacrophage conditions by upregulating genes involved in lipid degradation or inhibiting lipid biosynthesis (Betts et al., 2002; Rengarajan et al., 2005; Mukhopadhyay et al., 2012). As Mtb, Map adapts to the intracellular environment in the macrophage, where the bacteria overcome exposure to cationic antimicrobial peptides, reactive oxygen species (ROS) and nutrient starvation, via the regulation of genes affecting its envelope's composition (Thirunavukkarasu et al., 2014). In fact, a different lipid profile was previously observed in the envelope of intracellular Map after $1 \mathrm{~h}$ of infection (Alonso-Hearn et al., 2010; Everman et al., 2015). The full significance of these alterations in lipid metabolism had to be yet revealed to identify the issues facing Map within host macrophages. In addition, little data is available about how Map modulates FAs metabolism in response to the macrophage environment and whether this modulation is strain-specific and/or environmental-specific. Our study revealed that Map FAs composition changes upon macrophages infection and that these changes are strain dependent. Once within host macrophages, the intracellular FAs profiles of both Map isolates were equivalents regardless of the macrophage origin, bovine or ovine. Our findings support the idea that maintaining a particular FAs composition might confer certain advantage within the host cell environment.

In conclusion, our results provide evidence that the clinical spectrum of paratuberculosis may be dictated by the surface exposed FAs defined by each Map strain. The K10 strain that had more TBSA and less Palmitic acid than the 2349/06-1 isolate was highly successful in establishing an infection in macrophages likely by having a more favorable PIMs engagement of the MR on macrophages. Since the TBSA is a lipid tail of PIMs exclusively found in the cell wall of the genus Mycobacterium, we can conclude that structural modifications of the PI anchor may represent a mechanism 
for mycobacteria to gain advantage in establishing infection. Moreover, we show that the FAs profiles of two different Map isolates change during host cell infection and provide novel insights into the metabolic adaptation of Map within host macrophages. Our study provides new targets for derivation of attenuated Map strains by targeted gene disruption and reveals the intrincate connection between metabolism and virulence in Map.

\section{AUTHOR CONTRIBUTIONS}

$\mathrm{MAH}$ designed the study and drafted the manuscript. NA conducted Map infection experiments. MR and RA performed FAME extraction, GC, and FAMEs pattern recognition and cluster analysis. RJ and ML analyzed the FAs database and generated the GLM and the NFL models, respectively. All the authors helped in the interpretation of the obtained data, revised the manuscript critically for important intellectual content and gave the final approval of the version to be published. In addition, all the authors agreed to be accountable for all aspects of the work in ensuring that questions related to the accuracy or integrity of any part of the work are appropriately investigated and resolved.

\section{REFERENCES}

Abendaño, N., Sevilla, I. A., Prieto, J. M., Garrido, J. M., Juste, R. A., and AlonsoHearn, M. (2013). Mycobacterium avium subspecies paratuberculosis isolates from sheep and goats show reduced persistence in bovine macrophages than cattle, bison, deer and wild boar strains regardless of genotype. Vet. Microbiol. 163, 325-334. doi: 10.1016/j.vetmic.2012.12.042

Abendaño, N., Tyukalova, L., Barandika, J. F., Balseiro, A., Sevilla, I. A., Garrido, J. M., et al. (2014). Mycobacterium avium subsp. paratuberculosis isolates induce in vitro granuloma formation and show succesful survival phenotype, common anti-inflammatory and antiapoptotic responses within ovien macrophages regardless og genotype or host of origin. PLoS ONE 9:e104238. doi: 10.1371/journal.pone.0104238

Abubakar, I., Myhill, D., Aliyu, S. H., and Hunter, P. R. (2008). Detection of Mycobacterium avium subspecies paratuberculosis from patients with Crohn's disease using nucleic acid-based techniques: a systematic review and metaanalysis. Inflamm. Bowel Dis. 14, 401-410. doi: 10.1002/ibd.20276

Adúriz, J. J., Juste, R. A., and Cortabarria, N. (1995). Lack of mycobactin dependence of mycobacteria isolated on Middlebrook 7H11 from clinical cases of ovine paratuberculosis. Vet. Microbiol. 45, 211-217.

Albesa-Jové, D., Svetlíková, Z., Tersa, M., Sancho-Vaello, E., Carreras-González, A., Bonnet, P., et al. (2016). Structural basis for selective recognition of acyl chains by the membrane-associated acyltransferase PatA. Nat. Commun. 7:10906. doi: 10.1038/ncomms10906

Alonso-Hearn, M., Eckstein, T. M., Sommer, S., and Bermudez, L. E. (2010). A Mycobacterium avium subsp. paratuberculosis LuxR regulates cell envelope and virulence. Innate Immun. 16, 235-247. doi: 10.1177/1753425909339811

Asselineau, C., Clavel, S., Clément, F., Daffé, M., David, H., Lanéelle, M. A., et al. (1981). Lipidic constituents of "Mycobacterium leprae" isolated from experimentally infected armadillo. Ann. Microbiol. 132A, 19-30.

Betts, J. C., Lukey, P. T., Robb, L. C., McAdam, R. A., and Duncan, K. (2002). Evaluation of a nutrient starvation model of Mycobacterium tuberculosis persistence by gene and protein expression profiling. Mol. Microbiol. 43, 717-731. doi: 10.1046/j.1365-2958.2002.02779.x

Bryant, J. M., Thibault, V. C., Smith, D. G., McLuckie, J., Heron, I., Sevilla, I. A., et al. (2016). Phylogenomic exploration of the relationships between strains

\section{FUNDING}

Financial support for this work was provided by grants from the Instituto Nacional de Investigación y Tecnología Agraria y Alimentaria (INIA) and by European Funds for Regional Development (FEDER) (RTA2011-00049; RTA2014-00009) to $\mathrm{MAH}$. Additional support is provided by a grant from the Xunta of Galicia (ED431C 2016/008). NA had a fellowship from the department of Agriculture of the Basque Government.

\section{ACKNOWLEDGMENTS}

We would like to thank Judith Stabel at the National Animal Disease Research Unit, USDA-ARS, in Ames, IA, for the generous gift of the BOMAC cell line. We are also in debt with Michel Olivier (INRA, France) for the MOCL- 4 cell line. We are grateful to Kyle Hearn for the careful editing of the manuscript.

\section{SUPPLEMENTARY MATERIAL}

The Supplementary Material for this article can be found online at: http://journal.frontiersin.org/article/10.3389/fcimb. 2017.00089/full\#supplementary-material

of Mycobacterium avium subspecies paratuberculosis. BMC Genomics 17:79. doi: 10.1186/s12864-015-2234-5

Cai, G., Pauli, G. F., Wang, Y., Jaki, B. U., and Franzblau, S. G. (2013). Rapid determination of growth inhibition of Mycobacterium tuberculosis by GC-MS/MS quantitation of tuberculostearic acid. Tuberculosis 93, 322-329. doi: 10.1016/j.tube.2012.12.004

Chiodini, R. J., and Van Kruiningen, H. J. (1985). Characterization of Mycobacterium paratuberculosis of bovine, caprine, and ovine origin by gasliquid chromatographic analysis of fatty acids in whole-cell extracts. Am. J. Vet. Res. 46, 1980-1989.

Colbourn, E. A., and Rowe, R. C. (2009). Novel approaches to neural and evolutionary computing in pharmaceutical formulation: challenges and new possibilities. Future Med. Chem. 1, 713-726. doi: 10.4155/fmc.09.57

Collins, D. M., Gabric, D. M., and de Lisle, G. W. (1990). Identification of two groups of Mycobacterium paratuberculosis strains by restriction endonuclease analysis and DNA hybridization. J. Clin. Microbiol. 28, 1591-1596.

Dang, N. A., Mourão, M., Kuijper, S., Walters, E., Janssen, H. G., and Kolk, A. H. (2015). Direct detection of Mycobacterium tuberculosis in sputum using combined solid phase extraction-gas chromatography-mass spectrometry. J. Chromatogr. B Analyt. Technol. Biomed. Life Sci. 986-987, 115-122. doi: 10.1016/j.jchromb.2015.01.045

Everman, J. L., Eckstein, T. M., Roussey, J., Coussens, P., Bannantine, J. P., and Bermudez, L. E. (2015). Characterization of the inflammatory phenotype of Mycobacterium avium subspecies paratuberculosis using a novel cell culture passage model. Microbiology 161, 1420-1434. doi: 10.1099/mic.0.000106

Feller, M., Huwiler, K., Stephan, R., Altpeter, E., Shang, A., Furrer, H., et al. (2007). Mycobacterium avium subspecies paratuberculosis and Crohn's disease: a systematic review and meta-analysis. Lancet Infect. Dis. 7, 607-613. doi: 10.1016/S1473-3099(07)70211-6

Fratti, R. A., Chua, J., Vergne, I., and Deretic, V. (2003). Mycobacterium tuberculosis glycosylated phosphatidylinositol causes phagosome maturation arrest. Proc. Natl. Acad. Sci. U.S.A. 100, 5437-5442. doi: 10.1073/ pnas.0737613100

Gago, J., Martínez-Núñez, L., Landín, M., and Gallego, P. P. (2010). Artificial neural networks as an alternative to the traditional statistical methodology in plant research. J. Plant. Physiol. 167, 23-27. doi: 10.1016/j.jplph.2009.07.007 
Gilleron, M., Lindner, B., and Puzo, G. (2006). MS/MS approach for characterization of the fatty acid distribution on mycobacterial phosphatidylmyo-inositol mannosides. Anal. Chem. 78, 8543-8548. doi: 10.1021/ac061574a

Gilleron, M., Quesniaux, V. F. J., and Puzo, G. (2003). Acylation state of the phosphatidylinositol hexamannosides from Mycobacterium bovis bacillus Calmette Guérin and Mycobacterium tuberculosis H37Rv and its implication in Toll-like receptor response. J. Biol. Chem. 278, 29880-29889. doi: 10.1074/jbc.M303446200

Gilleron, M., Ronet, C., Mempe, M., Monsarrat, B., Gachelin, G., and Puzo, G. (2001). Acylation state of the phosphatidylinositol mannosides from Mycobacterium bovis bacillus Calmette Guérin and ability to induce granuloma and recruit natural killer T cells. J. Biol. Chem. 276, 34896-34904. doi: 10.1074/jbc.M103908200

Guerin, M. E., Korduláková, J., Alzari, P. M., Brennan, P. J., and Jackson, M. (2010). Molecular basis of phosphatidyl-myo-inositol mannoside biosynthesis and regulation in mycobacteria. J. Biol. Chem. 285, 33577-33583. doi: $10.1074 / j b c . R 110.168328$

Juste, R. A., Elguezabal, N., Garrido, J. M., Pavon, A., Geijo, M. V., Sevilla, I., et al. (2008). On the prevalence of M. avium subspecies paratuberculosis DNA in the blood of healthy individuals and patients with inflammatory bowel disease. PLOS ONE 3:e2537. doi: 10.1371/journal.pone.0002537

Juste, R. A., Elguezabal, N., Pavón, A., Garrido, J. M., Geijo, M., Sevilla, I., et al. (2009). Association between Mycobacterium avium subsp. paratuberculosis DNA in blood and cellular and humoral immune response in inflammatory bowel disease patients and controls. Int. J. Infect. Dis. 13, 247-254. doi: 10.1016/ j.ijid.2008.06.034

Kolattukudy, P. E., Fernandes, N. D., Azad, A. K., Fitzmaurice, A. M., and Sirakova, T. D. (1997). Biochemistry and molecular genetics of cell-wall lipid biosynthesis in mycobacteria. Mol. Microbiol. 24, 263-270.

Lambert, M. A., Moss, C. W., Silcox, V. A., and Good, R. C. (1986). Analysis of mycolic acid cleavage products and cellular fatty acids of Mycobacterium species by capillary gas chromatography. J. Clin. Microbiol. 23, 731-736.

Landín, M., Rowe, R. C., and York, P. (2009). Advantages of neurofuzzy logic against conventional experimental design and statistical analysis in studying and developing direct compression formulations. Eur. J. Pharm. Sci. 38, 325-331. doi: 10.1016/j.ejps.2009.08.004

Li, Y., Powell, D. A., Shaffer, S. A., Rasko, D. A., Pelletier, M. R., Leszyk, J. D., et al. (2012). LPS remodeling is an evolved survival strategy for bacteria. Proc. Natl. Acad. Sci. U.S.A. 109, 8716-8721. doi: 10.1073/pnas.1202908109

Luquin, M., Ausina, V., López Calahorra, F., Belda, F., García Barceló, M., Celma, C., et al. (1991). Evaluation of practical chromatographic procedures for identification of clinical isolates of mycobacteria. J. Clin. Microbiol. 29, 120-130.

Majumder, N., Bhattacharjee, S., Dey, R., Bhattacharyya Majumdar, S., Pal, N. K., and Majumdar, S. (2008). Arabinosylated lipoarabinomannan modulates the impaired cell mediated immune response in Mycobacterium tuberculosis $\mathrm{H} 37 \mathrm{Rv}$ infected C57BL/6 mice. Microbes Infect. 10, 349-357. doi: 10.1016/j.micinf.2007.12.013

Mukhopadhyay, S., Nair, S., and Ghosh, S. (2012). Pathogenesis in tuberculosis: transcriptomic approaches to unraveling virulence mechanisms and finding new drug targets. FEMS Microbiol. Rev. 36, 463-485. doi: 10.1111/j.1574-6976.2011.00302.x

Naser, S. A., Sagramsingh, S. R., Naser, A. S., and Thanigachalam, S. (2014). Mycobacterium avium subspecies paratuberculosis causes Crohn's disease in some inflammatory bowel disease patients. World J. Gastroenterol. 20, 7403-7415. doi: 10.3748/wjg.v20.i23.7403

Odham, G., Larsson, L., and Mårdh, P. A. (1979). Demonstration of tuberculostearic acid in sputum from patients with pulmonary tuberculosis by selected ion monitoring. J. Clin. Invest. 63, 813-819. doi: 10.1172/JCI109380

Olivier, M., Berthon, P., Chastang, J., Cordier, G., and Lantier, F. (2001). Establishment and characterisation of ovine blood monocyte-derived cell lines. Vet. Immunol. Immunopathol. 82, 139-151. doi: 10.1016/S0165-2427 (01)00330-0

Ott, S. L., Wells, S. J., and Wagner, B. A. (1999). Herd-level economic losses associated with Johne's disease on US dairy operations. Prev. Vet. Med. 40, 179-192.

Ozbek, A., and Aktas, O. (2003). Identification of three strains of Mycobacterium species isolated from clinical samples using fatty acid methyl ester profiling. J. Int. Med. Res. 31, 133-140. doi: 10.1177/147323000303100210
Rengarajan, J., Bloom, B. R., and Rubin, E. J. (2005). Genome-wide requirements for Mycobacterium tuberculosis adaptation and survival in macrophages. Proc Natl Acad Sci U.S.A. 102, 8327-8332. doi: 10.1073/pnas.0503272102

Rivière, M., Moisand, A., Lopez, A., and Puzo, G. (2004). Highly ordered supramolecular organization of the mycobacterial lipoarabinomannans in solution. Evidence of a relationship between supra-molecular organization and biological activity. J. Mol. Biol. 344, 907-918. doi: 10.1016/j.jmb.2004.09.092

Sasser, M. (1990). Identification of bacteria by gas chromatography of cellular fatty acids. MIDI Technical Note.

Scanu, A. M., Bull, T. J., Cannas, S., Sanderson, J. D., Sechi, L. A., Dettori, G., et al. (2007). Mycobacterium avium subspecies paratuberculosis infection in cases of irritable bowel syndrome and comparison with Crohn's disease and Johne's disease: common neural and immune pathogenicities. J. Clin. Microbiol. 45, 3883-3890. doi: 10.1128/JCM.01371-07

Sevilla, I. A., Singh, S. V., Garrido, J. M., Aduriz, G., Rodríguez, S., Geijo, M. V., et al. (2005). Molecular typing of Mycobacterium avium subspecies paratuberculosis strains from different hosts and regions. Rev. Sci. Tech. 24, 1061-1066. doi: 10.20506/rst.24.3.1634

Sevilla, I., Garrido, J. M., Geijo, M., and Juste, R. A. (2007). Pulsed-field gel electrophoresis profile homogeneity of Mycobacterium avium subsp. paratuberculosis isolates from cattle and heterogeneity of those from sheep and goats. BMC Microbiol. 7:18. doi: 10.1186/1471-2180-7-18

Shao, Q., Rowe, R. C., and York, P. (2006). Comparison of neurofuzzy logic and neural networks in modelling experimental data of an immediate release tablet formulation. Eur. J. Pharm. Sci. 28, 394-404. doi: 10.1016/j.ejps.2006.04.007

Souza, C. D., Evanson, O. A., Sreevatsan, S., and Weiss, D. J. (2007). Cell membrane receptors of bovine mononuclear phagocytes involved on phagocytosis of Mycobcaterium avium subsp. paratuberculosis. Am. J. Vet. Res. 68, 975-980. doi: 10.2460/ajvr.68.9.975

Souza, C., Davis, W. C., Eckstein, T. M., Sreevatsan, S., and Weiss, D. J. (2013). Mannosylated lipoarabinomannans from Mycobacterium avium subsp. paratuberculosis alters the inflammatory response by bovine macrophages and suppresses killing of Mycobacterium avium subsp. avium organisms. PLoS ONE 8:e75924. doi: 10.1371/journal.pone.0075924

Stabel, J. R., and Stabel, T. J. (1995). Immortalization and characterization of bovine peritoneal macrophages transfected with SV40 plasmid DNA.Vet. Immunol. Immunopathol. 45, 211-220.

Thirunavukkarasu, S., de Silva, K., Plain, K. M., and Whittington, R. (2014). Role of host- and pathogen-associated lipids in directing the immune response in mycobacterial infections, with emphasis on Mycobacterium avium subsp. paratuberculosis. Crit. Rev. Microbiol. 42, 262-275. doi: 10.3109/1040841X.2014.932327

Torrelles, J. B., Azad, A. K., and Schlesinger, L. S. (2006). Fine discrimination in the recognition of individual species of phosphatidyl-myo-inositol mannosides from Mycobacterium tuberculosis by C-type lectin pattern recognition receptors. J. Immunol. 177, 1805-1816. doi: 10.4049/jimmunol.177. 3.1805

Torrelles, J. B., Knaup, R., Kolareth, A., Slepushkina, T., Kaufman, T. M., Kang, P., et al. (2008). Identification of Mycobacterium tuberculosis clinical isolates with altered phagocytosis by human macrophages due to a truncated lipoarabinomannan. J. Biol. Chem. 283, 31417-31428. doi: 10.1074/jbc M806350200

Torrelles, J. B., and Schlesinger, L. S. (2010). Diversity in Mycobacterium tuberculosis mannosylated cell wall determinants impacts adaptation to the host. Tuberculosis 90, 84-93. doi: 10.1016/j.tube.2010. 02.003

Conflict of Interest Statement: The authors declare that the research was conducted in the absence of any commercial or financial relationships that could be construed as a potential conflict of interest.

Copyright ( 2017 Alonso-Hearn, Abendaño, Ruvira, Aznar, Landin and Juste. This is an open-access article distributed under the terms of the Creative Commons Attribution License (CC BY). The use, distribution or reproduction in other forums is permitted, provided the original author(s) or licensor are credited and that the original publication in this journal is cited, in accordance with accepted academic practice. No use, distribution or reproduction is permitted which does not comply with these terms. 